DOI: $10.17816 /$ byusu20180138-45

УДК 621.31

A. Kushnerov

\title{
TRANSIENT AND STEADY-STATE ANALYSIS OF SINGLE SWITCHED CAPACITOR CONVERTER
}

Abstract-The paper derives closed form expressions for transient and steady-state operation of a DC$D C$ converter with single switched capacitor. To this end, the result of each switching is considered as a point in the iterative process, and the function between the points is reconstructed. As opposed to the commonly accepted approach, when each of the topologies is approximated by a first order circuit, the proposed analysis is carried out for second order circuits. This allows obtaining the waveform of output voltage ripple and paves the way to more accurate calculation of equivalent resistance. The obtained analytical expressions were verified by simulations and an excellent agreement between the results was found.

Index terms - charge pump, discrete-time systems, equivalent resistance, switched capacitor converter.

\section{Introduction}

Switched capacitor converters (SCCs) are favored in some applications due to low EMI and compatibility with IC technology. Over the past few decades, ongoing research has shifted towards sophisticated SCCs with large number of capacitors and advanced control circuits. However, only a few studies use analytical methods. The analysis presented in this paper is based on the method of difference equations (Gardner \& Barnes, 1942), (Tsypkin, 1964), (Derusso, Roy, \& Close, 1965), which allows finding the solution for the transient and steady-state operation. Although this method is unified, it was applied previously only to the switched inductor converters (Nerone, 2008), (Shoihet \& Slonim, 2010), (Krihely, Slonim, \& Ben-Yaakov, 2012). However, some analytical methods for analysis of switched capacitor circuits that bear resemblance of the proposed one, were presented in (Lamantia, Maranesi, \& Radrizzani, 1994), (Vitchev, 2006), (Karagozler, Goldstein, \& Ricketts, 2012), (Ramezani \& Yakovlev, 2013).

Let us consider the SCC shown schematically in Fig. 1(a). It comprises four switches $S_{1} \ldots S_{4}$ with onresistances $r_{1} \ldots r_{4}$. The corresponding pair of switches is turned on/off by two non-overlapping clocks $\varphi_{1}$ and $\varphi_{2}$ shown in Fig. 1(b). Thus, during $t_{1}$ the capacitor $C_{1}$ is charged by $V_{i n}$ through $S_{1}, S_{3}$ and then, during $t_{2}$, is discharged to the load through $S_{2}, S_{4}$. Thus, we have two topologies, which are considered separately in Sections II. Applying to each topology the Kirchhoff's voltage and current laws (KVL and KCL), we write a system of two first-order differential equations. These equations are then solved using the Laplace transform. The solution for the first topology defines the initial conditions for the second one. This enables us to compose a system of two first-order difference equations, which is solved using the Z-transform. Thus, for a given period, $n$, we know the initial values of state variables and functions according to which these variables change. This is the solution is closed form.

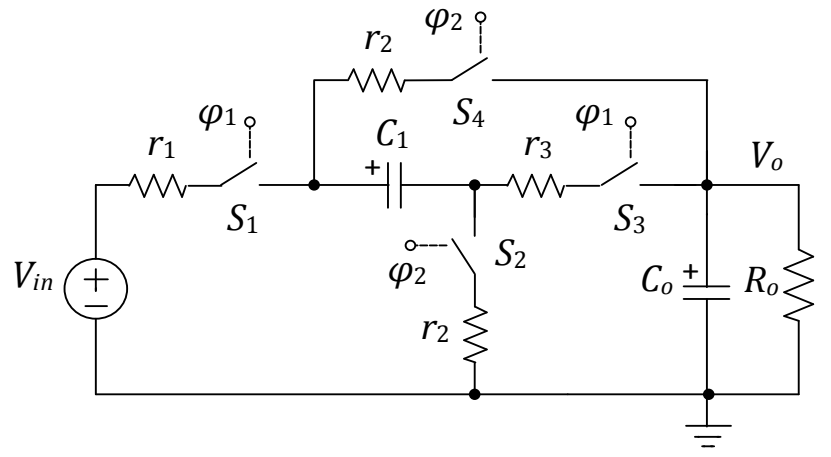

a)

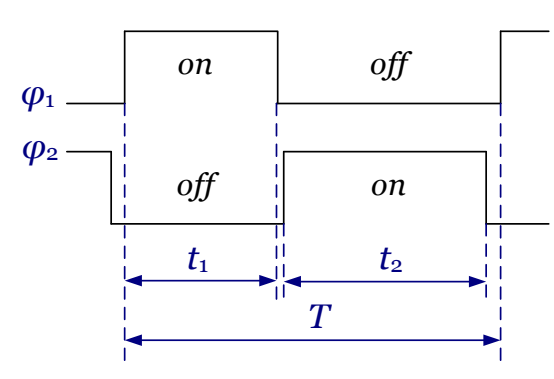

b)

Fig. 1: Considered SCC (a) and two non-overlapping clocks $\varphi_{1}$ and $\varphi_{2}$ (b). 


\section{Differential Equations}

a) First topology

The switches $S_{1}$ and $S_{3}$ in Fig. 1(a) are turned on during $n T \leq t<n T+t_{1}$, where $n$ is the number of period. Thus, in the first topology (Fig. 2), $R_{1}=r_{1}+r_{3}$.

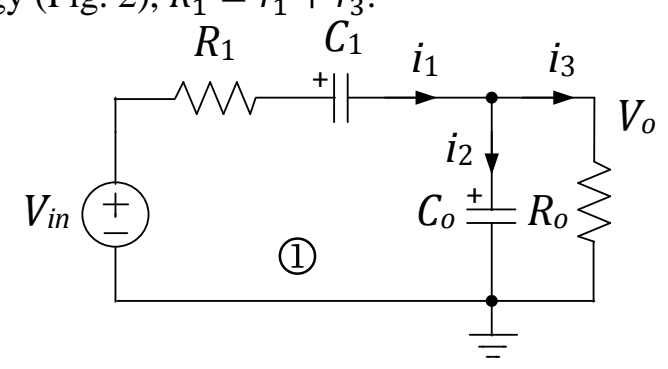

Fig. 2: First topology of the considered SCC.

The KVL and KCL equations for this circuit are:

$$
\left\{\begin{array} { l } 
{ V _ { \text { in } } = i _ { 1 } R _ { 1 } + V _ { C 1 } + V _ { C o } } \\
{ i _ { 1 } = i _ { 2 } + i _ { 3 } }
\end{array} \text { or } \left\{\begin{array}{l}
V_{\text {in }}=C_{1} \frac{d V_{C 1}}{d t} R_{1}+V_{C 1}+V_{C o} \\
C_{1} \frac{d V_{C 1}}{d t}=C_{o} \frac{d V_{C o}}{d t}+\frac{V_{C o}}{R_{o}}
\end{array}\right.\right.
$$

Let us write (1) in the Laplace domain using

such that

$$
\mathcal{L}\{K\}=\frac{K}{s} \quad \text { and } \quad \mathcal{L}\left\{\frac{d f(x)}{d x}\right\}=s F(s)-f(0)
$$

$$
\left\{\begin{array}{l}
\left(s R_{1} C_{1}+1\right) V_{C 1}+V_{C o}=R_{1} C_{1} V_{C 1}(n)+\frac{V_{i n}}{s} \\
-s C_{1} V_{C 1}+\left(s C_{o}+\frac{1}{R_{o}}\right) V_{C o}=C_{o} V_{C o}(n)-C_{1} V_{C 1}(n)
\end{array}\right.
$$

The solution of (3) can be written as:

where

$$
V_{C 1}=\frac{\left(s-r_{1}\right)\left(s-r_{2}\right)}{s\left(s-s_{1}\right)\left(s-s_{2}\right)} V_{C 1}(n) ; \quad V_{C o}=\frac{(s-p)}{\left(s-s_{1}\right)\left(s-s_{2}\right)} V_{C o}(n)
$$

and

$$
\begin{gathered}
r_{1,2}=-\lambda \pm \sqrt{\lambda^{2}-\frac{\omega_{0}^{2} V_{i n}}{V_{C 1}(n)}} ; \quad \lambda=\frac{1}{2}\left[\left(\frac{1}{R_{1}}+\frac{1}{R_{o}}\right) \frac{1}{C_{o}}+\frac{V_{i n}-V_{C o}(n)}{R_{1} C_{1} V_{C 1}(n)}\right] \\
p=-\left(\frac{V_{i n}-V_{C 1}(n)}{R_{1} C_{o} V_{C o}(n)}+\frac{1}{R_{1} C_{1}}\right)
\end{gathered}
$$

$$
s_{1,2}=-\alpha \pm \sqrt{\alpha^{2}-\omega_{0}^{2}} ; \quad \alpha=\frac{1}{2}\left[\left(\frac{1}{C_{1}}+\frac{1}{C_{o}}\right) \frac{1}{R_{1}}+\frac{1}{R_{o} C_{o}}\right] ; \quad \omega_{0}^{2}=\frac{1}{R_{1} C_{1} R_{o} C_{o}}
$$

The inverse Laplace transform of (4) is:

Using $t=t_{1}$ and

$$
\begin{gathered}
\mathcal{L}^{-1}\left\{V_{C 1}\right\}=\left(\frac{\left(r_{1}-s_{1}\right)\left(r_{2}-s_{1}\right)}{s_{1}\left(s_{1}-s_{2}\right)} e^{s_{1} t}-\frac{\left(r_{1}-s_{2}\right)\left(r_{2}-s_{2}\right)}{s_{2}\left(s_{1}-s_{2}\right)} e^{s_{2} t}+\frac{r_{1} r_{2}}{s_{1} s_{2}}\right) V_{C 1}(n) \\
\mathcal{L}^{-1}\left\{V_{C o}\right\}=\frac{\left(s_{2}-p\right) e^{s_{2} t}-\left(s_{1}-p\right) e^{s_{1} t}}{s_{2}-s_{1}} V_{C o}(n)
\end{gathered}
$$

we can rewrite (7) as:

$$
r_{1} r_{2}=\frac{\omega_{0}^{2} V_{i n}}{V_{C 1}(n)} ; \quad s_{1} s_{2}=\omega_{0}^{2} ; \quad r_{1}+r_{2}=-2 \lambda
$$


where

$$
\begin{gathered}
V_{C 1}\left(t_{1}\right)=a+b\left(V_{\text {in }}-V_{C o}(n)\right)+c V_{C 1}(n) \\
V_{C o}\left(t_{1}\right)=d\left(V_{\text {in }}-V_{C 1}(n)\right)+e V_{C o}(n)
\end{gathered}
$$

$$
\begin{gathered}
a=\left(1+\frac{s_{1} e^{s_{2} t_{1}}-s_{2} e^{s_{1} t_{1}}}{s_{2}-s_{1}}\right) V_{i n} ; \quad b=\frac{e^{s_{2} t_{1}}-e^{s_{1} t_{1}}}{s_{2}-s_{1}}\left(\frac{1}{R_{1} C_{1}}\right) ; \\
c=\frac{\left[s_{2}+\left(\frac{1}{R_{1}}+\frac{1}{R_{o}}\right) \frac{1}{C_{o}}\right] e^{s_{2} t_{1}}-\left[s_{1}+\left(\frac{1}{R_{1}}+\frac{1}{R_{o}}\right) \frac{1}{C_{o}}\right] e^{s_{1} t_{1}}}{s_{2}-s_{1}} ; \\
d=\frac{e^{s_{2} t_{1}}-e^{s_{1} t_{1}}}{s_{2}-s_{1}}\left(\frac{1}{R_{1} C_{o}}\right) ; \quad e=\frac{\left(s_{2}+\frac{1}{R_{1} C_{1}}\right) e^{s_{2} t_{1}}-\left(s_{1}+\frac{1}{R_{1} C_{1}}\right) e^{s_{1} t_{1}}}{s_{2}-s_{1}}
\end{gathered}
$$

b) Second topology

The switches $S_{2}$ and $S_{4}$ in Fig. 1(a) are turned on during $n T+t_{1} \leq t<(n+1) T$, such that in the second topology (Fig. 3) $R_{2}=r_{2}+r_{4}$.

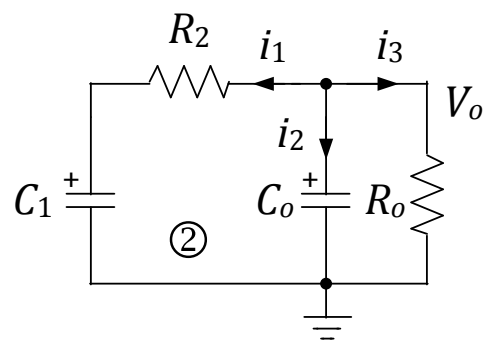

Fig. 3: Second topology of the considered SCC.

The KVL and KCL equations for this circuit are:

$$
\left\{\begin{array} { l } 
{ V _ { C 1 } = - i _ { 1 } R _ { 2 } + V _ { C o } } \\
{ - i _ { 1 } = i _ { 2 } + i _ { 3 } }
\end{array} \text { or } \left\{\begin{array}{l}
V_{C 1}=-C_{1} \frac{d V_{C 1}}{d t} R_{2}+V_{C o} \\
-C_{1} \frac{d V_{C 1}}{d t}=C_{o} \frac{d V_{C o}}{d t}+\frac{V_{C o}}{R_{o}}
\end{array}\right.\right.
$$

Using (2), we write (11) in the Laplace domain:

$$
\left\{\begin{array}{l}
\left(s R_{2} C_{1}+1\right) V_{C 1}-V_{C o}=R_{2} C_{1} V_{C 1}(n) \\
s C_{1} V_{C 1}+\left(s C_{o}+\frac{1}{R_{o}}\right) V_{C o}=C_{1} V_{C 1}(n)+C_{o} V_{C o}(n)
\end{array}\right.
$$

The solution of (12) is:

where

$$
V_{C 1}=\frac{\left(s-p_{1}\right)}{\left(s-s_{1}\right)\left(s-s_{2}\right)} V_{C 1}(n) ; \quad V_{C o}=\frac{\left(s-p_{2}\right)}{\left(s-s_{1}\right)\left(s-s_{2}\right)} V_{C o}(n)
$$

and

$$
p_{1}=-\left(\frac{V_{C 1}(n)}{C_{o} V_{C o}(n)}+\frac{1}{C_{1}}\right) \frac{1}{R_{2}} ; \quad p_{2}=-\left(\frac{1}{R_{o}}+\frac{1}{R_{2}}\right) \frac{1}{C_{o}}-\left(\frac{1}{R_{2} C_{1}}\right) \frac{V_{C o}(n)}{V_{C 1}(n)}
$$

$$
s_{1,2}=-\alpha \pm \sqrt{\alpha^{2}-\omega_{0}^{2}} ; \quad \alpha=\frac{1}{2}\left[\left(\frac{1}{C_{1}}+\frac{1}{C_{o}}\right) \frac{1}{R_{2}}+\frac{1}{R_{o} C_{o}}\right] ; \quad \omega_{0}^{2}=\frac{1}{R_{2} C_{1} R_{o} C_{o}}
$$

The inverse Laplace transform of (13) is:

$$
\begin{aligned}
& \mathcal{L}^{-1}\left\{V_{C 1}\right\}=\frac{\left(s_{2}-p_{1}\right) e^{s_{2} t}-\left(s_{1}-p_{1}\right) e^{s_{1} t}}{s_{2}-s_{1}} V_{C 1}(n) \\
& \mathcal{L}^{-1}\left\{V_{C o}\right\}=\frac{\left(s_{2}-p_{2}\right) e^{s_{2} t}-\left(s_{1}-p_{2}\right) e^{s_{1} t}}{s_{2}-s_{1}} V_{C o}(n)
\end{aligned}
$$


Since for the second topology $t_{1} \leq t \leq t_{2}$, the initial conditions will be $V_{C 1}(n)=V_{C 1}\left(t_{1}\right)$ and $V_{C o}(n)=$ $V_{C o}\left(t_{1}\right)$, whereas $t=t_{2}-t_{1}$.

\section{Difference Equations}

Substituting (14) and (15) into (16), we obtain the recurrent equations:

where

$$
V_{C 1}(n+1)=f V_{C 1}\left(t_{1}\right)+g V_{C o}\left(t_{1}\right) ; \quad V_{C o}(n+1)=h V_{C 1}\left(t_{1}\right)+k V_{C o}\left(t_{1}\right)
$$

$$
\begin{gathered}
f=\frac{\left(s_{2}+\left(\frac{1}{R_{o}}+\frac{1}{R_{2}}\right) \frac{1}{C_{o}}\right) e^{s_{2}\left(t_{2}-t_{1}\right)}-\left(s_{1}+\left(\frac{1}{R_{o}}+\frac{1}{R_{2}}\right) \frac{1}{C_{o}}\right) e^{s_{1}\left(t_{2}-t_{1}\right)}}{s_{2}-s_{1}} \\
g=\frac{e^{s_{2}\left(t_{2}-t_{1}\right)}-e^{s_{1}\left(t_{2}-t_{1}\right)}\left(\frac{1}{R_{2} C_{1}}\right) ; \quad h=\frac{e^{s_{2}\left(t_{2}-t_{1}\right)}-e^{s_{1}\left(t_{2}-t_{1}\right)}}{s_{2}-s_{1}}\left(\frac{1}{R_{2} C_{o}}\right)}{k=\frac{\left(s_{2}+\frac{1}{R_{2} C_{1}}\right) e^{s_{2}\left(t_{2}-t_{1}\right)}-\left(s_{1}+\frac{1}{R_{2} C_{1}}\right) e^{s_{1}\left(t_{2}-t_{1}\right)}}{s_{2}-s_{1}}}
\end{gathered}
$$

Now, substituting (9) into (17), we obtain the difference equations:

where

$$
\left\{\begin{array}{l}
V_{C 1}(n+1)=A+B V_{C o}(n)+G V_{C 1}(n) \\
V_{C o}(n+1)=E+F V_{C o}(n)+H V_{C 1}(n)
\end{array}\right.
$$

$$
\begin{aligned}
& A=(f b+g d) V_{i n}+f a ; B=g e-f b ; G=f c-g d \\
& E=(h b+k d) V_{i n}+h a ; \quad F=k e-h b ; H=h c-k d
\end{aligned}
$$

Before we proceed to the solution of (19), let us consider the steady-state operation, where

$$
V_{C 1}(n+1)=V_{C 1}(n) ; \quad V_{C o}(n+1)=V_{C o}(n)
$$

substituting (21) into (19), we have

$$
\left\{\begin{array}{l}
(G-1) V_{C 1}(n)+B V_{C o}(n)=-A \\
H V_{C 1}(n)+(F-1) V_{C o}(n)=-E
\end{array}\right.
$$

The solution of (22) is:

$$
V_{C 1}(n)=\frac{B E-A(F-1)}{(F-1)(G-1)-B H} ; \quad V_{C o}(n)=\frac{H A-E(G-1)}{(F-1)(G-1)-B H}
$$

Let us write (19) in the Z-domain using

such that

$$
Z\{K\}=K \frac{Z}{Z-1} \quad \text { and } \quad Z\{f(n+1)\}=z F(n)-f(0)
$$

$$
\left\{\begin{array}{c}
(z-G) V_{C 1}(z)-B V_{C o}(z)=A \frac{z}{z-1}+z V_{C 1}(0) \\
-H V_{C 1}(z)+(z-F) V_{C o}(z)=E \frac{z}{z-1}+z V_{C o}(0)
\end{array}\right.
$$

The solution of (25) is:

where

$$
\begin{aligned}
& V_{C 1}(z)=\frac{(z-F) V_{C 1}(0)+B V_{C o}(0)}{\left(z-z_{1}\right)\left(z-z_{2}\right)} z+\frac{(z-F) A+B E}{\left(z-z_{1}\right)\left(z-z_{2}\right)}\left(\frac{z}{z-1}\right) \\
& V_{C o}(z)=\frac{H V_{C 1}(0)+(z-G) V_{C o}(0)}{\left(z-z_{1}\right)\left(z-z_{2}\right)} z+\frac{H A+(z-G) E}{\left(z-z_{1}\right)\left(z-z_{2}\right)}\left(\frac{z}{z-1}\right)
\end{aligned}
$$

$$
z_{1,2}=\frac{G+F \pm \sqrt{(G+F)^{2}-4(G F-B H)}}{2}
$$


Since (26) is represented in the form of partial fractions, we can apply the inverse Z-transform to each term separately:

$$
\begin{array}{r}
V_{C 1}(n)=\frac{A\left(z_{2}-F\right)+B E}{z_{2}-z_{1}}\left(\frac{z_{2}^{n}-1}{z_{2}-1}\right)-\frac{A\left(z_{1}-F\right)+B E}{z_{2}-z_{1}}\left(\frac{z_{1}^{n}-1}{z_{1}-1}\right)+ \\
\frac{\left(z_{2}-F\right) z_{2}^{n}-\left(z_{1}-F\right) z_{1}^{n}}{z_{2}-z_{1}} V_{C 1}(0)+\frac{z_{2}^{n}-z_{1}^{n}}{z_{2}-z_{1}} B V_{C o}(0) \\
V_{C o}(n)=\frac{E\left(z_{2}-G\right)+A H}{z_{2}-z_{1}}\left(\frac{z_{2}^{n}-1}{z_{2}-1}\right)-\frac{E\left(z_{1}-G\right)+A H}{z_{2}-z_{1}}\left(\frac{z_{1}^{n}-1}{z_{1}-1}\right)+ \\
\frac{\left(z_{2}-G\right) z_{2}^{n}-\left(z_{1}-G\right) z_{1}^{n}}{z_{2}-z_{1}} V_{C o}(0)+\frac{z_{2}^{n}-z_{1}^{n}}{z_{2}-z_{1}} H V_{C 1}(0)
\end{array}
$$

\section{Simulation Results}

To verify the obtained analytical expressions (9), (17) and (28), the circuit shown in Fig. 4 was simulated in PSIM 9.0. Since the PSIM bidirectional switches have zero on-resistance, two external resistors corresponding to $R_{1}$ and $R_{2}$ in Fig. 2 and Fig. 3 were added. The parameters of the circuit in Fig. 4 are as follows: $V_{\text {in }}=10 \mathrm{~V}$, $V_{C 1}(0)=V_{C o}(0)=0 \mathrm{~V}, t_{1}=t_{2}=5 \mu \mathrm{s}, R_{1}=R_{2}=1 \Omega, C_{1}=10 \mu \mathrm{F}, R_{o}=100 \Omega$ and $C_{o}=100 \mu \mathrm{F}$.

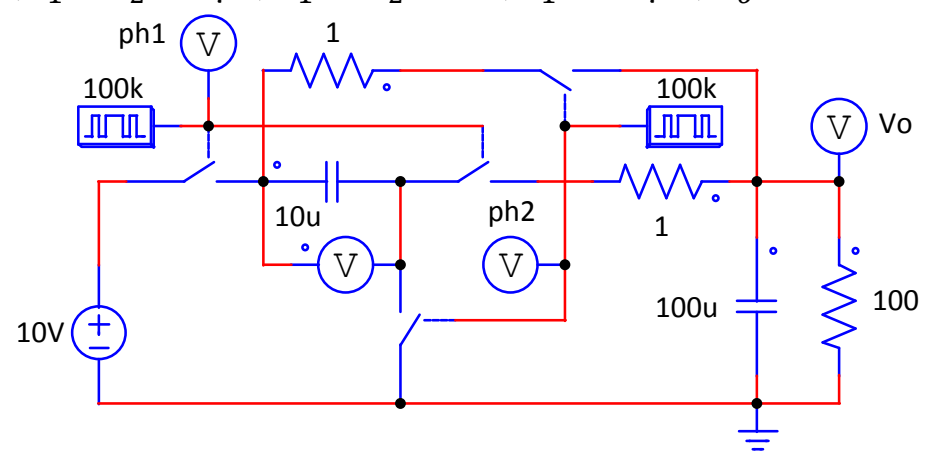

Fig. 4: Simulation circuit for the voltage-halving SCC.

Since $R_{1}=R_{2}$ and $t_{1}=t_{2}$, the expressions (10) and (18) are reduced to:

$$
\begin{aligned}
& a=\left(1+\frac{s_{1} e^{s_{2} t_{1}}-s_{2} e^{s_{1} t_{1}}}{s_{2}-s_{1}}\right) V_{i n} ; \quad b=g=\frac{e^{s_{2} t_{1}}-e^{s_{1} t_{1}}}{s_{2}-s_{1}}\left(\frac{1}{R_{1} C_{1}}\right) \\
& c=f=\frac{\left[s_{2}+\left(\frac{1}{R_{1}}+\frac{1}{R_{o}}\right) \frac{1}{C_{o}}\right] e^{s_{2} t_{1}}-\left[s_{1}+\left(\frac{1}{R_{1}}+\frac{1}{R_{o}}\right) \frac{1}{C_{o}}\right] e^{s_{1} t_{1}}}{s_{2}-s_{1}} ; \\
& e=k=\frac{\left(s_{2}+\frac{1}{R_{1} C_{1}}\right) e^{s_{2} t_{1}}-\left(s_{1}+\frac{1}{R_{1} C_{1}}\right) e^{s_{1} t_{1}}}{s_{2}-s_{1}} ; d=h=b \frac{C_{1}}{C_{o}}
\end{aligned}
$$

These constants are substituted into (20) and then into (28), which sets the initial conditions for (9) and (17). The voltages across $C_{1}$ and $C_{o}$ during the first ten periods $(0 \leq t \leq 10 T)$ is shown Fig. 5, which compares the MathCAD calculation and PSIM simulation. 


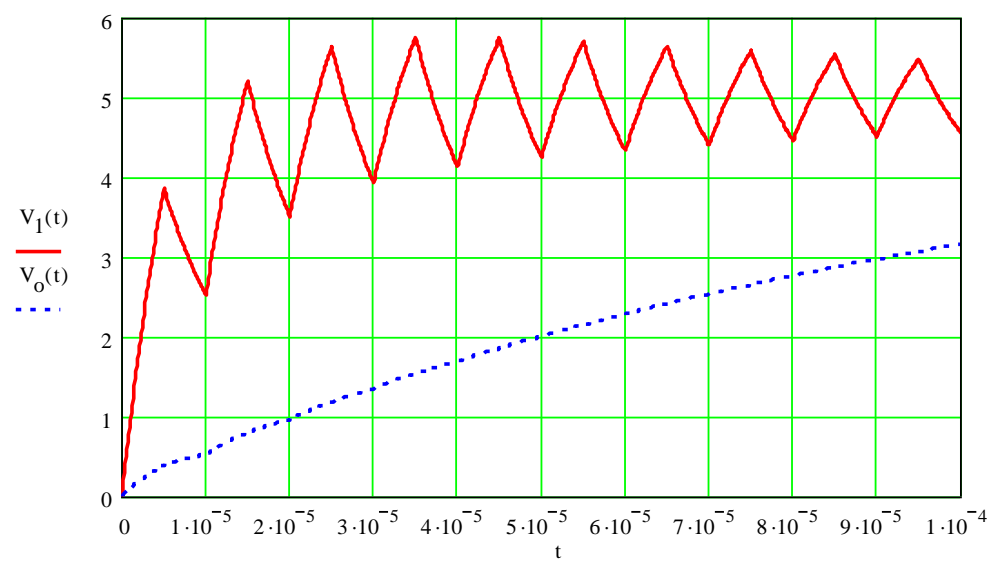

a)

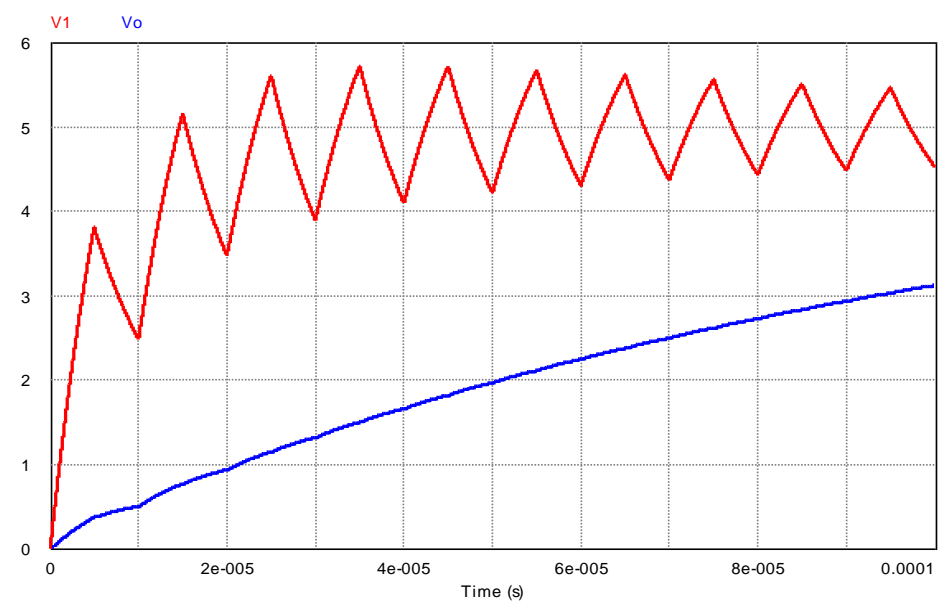

b)

Fig. 5: Voltages across $C_{1}$ and $C_{o}$ for $0 \leq t \leq 10 T$, MathCAD (a) and PSIM (b).

The horizontal scale is $10 \mu \mathrm{s} / \mathrm{div}$, i.e. each division is $T$.

The voltages in Fig. 5 were measured at the points $n T$ and are given in Table I along with the relative error, $\varepsilon$.

Table I: Measured values of the voltages in Fig. 5.

\begin{tabular}{|c|c|c|c|c|c|c|}
\hline \multirow{2}{*}{$\boldsymbol{n}$} & \multicolumn{2}{|c|}{$\boldsymbol{V}_{\boldsymbol{C 1}}(\boldsymbol{n})$} & \multirow{2}{*}{$\boldsymbol{\varepsilon}[\boldsymbol{\%}]$} & \multicolumn{3}{|c|}{$\boldsymbol{V}_{\boldsymbol{C o}}(\boldsymbol{n})$} \\
\cline { 2 - 3 } \cline { 5 - 6 } & Calc. & Simul. & & Calc. & Simul. & $\boldsymbol{\varepsilon}[\boldsymbol{\%}]$ \\
\hline 1 & 2.5146 & 2.5046 & 0.398 & 0.5174 & 0.5119 & 1.074 \\
\hline 2 & 3.4986 & 3.4937 & 0.140 & 0.9542 & 0.9449 & 0.984 \\
\hline 3 & 3.9147 & 3.9144 & 0.008 & 1.3381 & 1.3259 & 0.920 \\
\hline 4 & 4.1172 & 4.1193 & 0.051 & 1.6815 & 1.6670 & 0.870 \\
\hline 5 & 4.2366 & 4.2397 & 0.073 & 1.9909 & 1.9747 & 0.820 \\
\hline 6 & 4.3211 & 4.3254 & 0.010 & 2.2706 & 2.2531 & 0.777 \\
\hline 7 & 4.3890 & 4.3943 & 0.121 & 2.5236 & 2.5054 & 0.726 \\
\hline 8 & 4.4474 & 4.4534 & 0.135 & 2.7526 & 2.7339 & 0.684 \\
\hline 9 & 4.4991 & 4.5055 & 0.142 & 2.9601 & 2.9410 & 0.649 \\
\hline 10 & 4.5454 & 4.5455 & 0.002 & 7.1478 & 7.1282 & 0.627 \\
\hline
\end{tabular}

Fig. 6 compares the MathCAD calculation and PSIM simulation for $0 \leq t \leq 100 T$. Note that at $t \approx 60 T$ the SCC reaches the steady-state. 


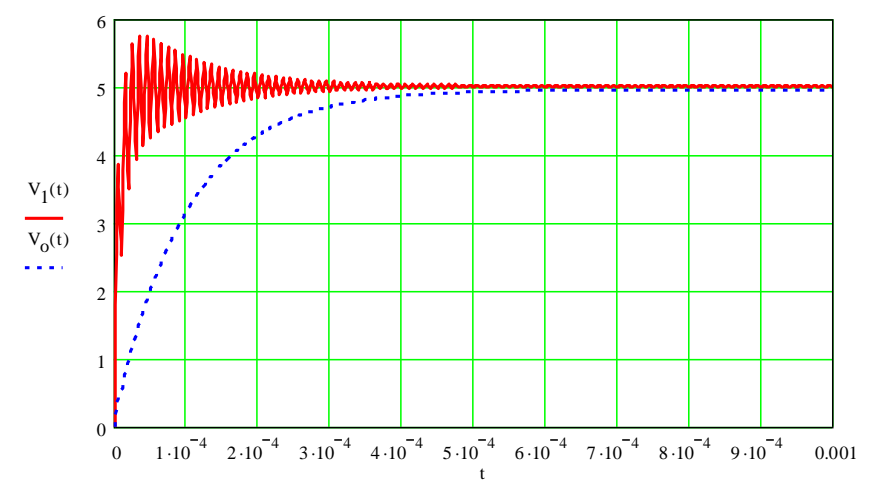

a)

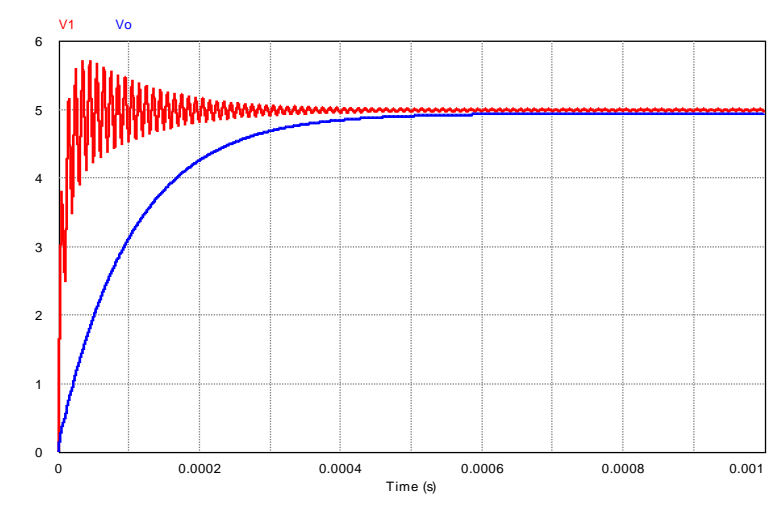

b)

Fig. 6: Voltages across $C_{1}$ and $C_{o}$ for $0 \leq t \leq 100 T$, MathCAD (a) and PSIM (b).

The horizontal scale is $100 \mu \mathrm{s} / \mathrm{div}$, i.e. each division is $10 \mathrm{~T}$.

The steady-state voltages are shown Fig. 7. Their discrete values were calculated by (23) and then substituted as the initial conditions into (9) and (17).

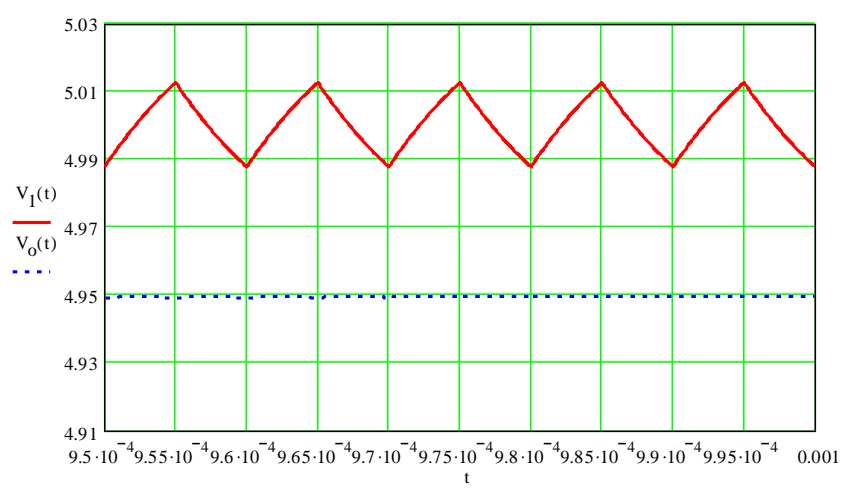

Fig. 7: Steady-state voltages across $C_{1}$ and $C_{o}$ for $95 T \leq t \leq 100 T$.

\section{Conclusion}

Based on the method of difference equations the closed form expressions for the voltages across the capacitors in the voltage-halving SCC were derived. The solution of these equations allows us to predict the SCC behavior in both the transient and steady-state operation. That is for a given period, $n$, we know the initial values of the voltages and functions according to which these voltages change. The obtained expressions were verified by simulations. As evident from Table I, the deviation between the theoretical and simulation results does not exceed $1.1 \%$. The used method however, is very complex even in the case of the two-phase SCC and its extension to the multi-phase SCC will apparently require some special assumptions.

\section{References}

1. M. F. Gardner and J. L. Barnes, Transients in Linear Systems, Studied by the Laplace Transformation, vol. I, Wiley, 1942. 
2. Y. Z. Tsypkin, Sampling Systems Theory and its Application, vol. I, Macmillan, 1964.

3. P. M. Derusso, R. J. Roy and C. M. Close, "§6.4 The Concept of State," in State Variables for Engineers, New York: Wiley, 1965, pp. 413-415.

4. L. R. Nerone, "Analytical solutions of the class D inverter," in IEEE International Symposium on Circuits and Systems (ISCAS), 2008.

5. Shoihet and M. A. Slonim, "Analysis of buck converter processes using difference equations method," in IEEE Convention of Electrical and Electronics Engineers in Israel (IEEEI), 2010.

6. N. Krihely, M. A. Slonim and S. Ben-Yaakov, "Transient and steady-state analysis of three-phase PWM buck rectifier," IET Power Electronics, vol. 5, no. 9, pp. 1764-1775, 2012.

7. Lamantia, P. Maranesi and L. Radrizzani, "Small-signal model of the Cockcroft-Walton voltage multiplier," IEEE Transactions on Power Electronics, vol. 9, no. 1, pp. 18-25, 1994.

8. V. Vitchev, "Calculating essential charge-pump parameters," Power Electronics Technology, vol. 7, pp. 30-45, 2006.

9. M. E. Karagozler, S. C. Goldstein and D. S. Ricketts, "Analysis and modeling of capacitive power transfer in microsystems," IEEE Transactions on Circuits and Systems I: Regular Papers, vol. 59, no. 7, pp. 1557-1566, 2012.

10.R. Ramezani and A. Yakovlev, "Capacitor discharging through asynchronous circuit switching," in IEEE Int. Symposium on Asynchronous Circuits and Systems (ASYNC), 2013. 